\title{
Perancangan dan Implementasi Knowledge Management Laboran Fakultas Teknologi Informasi Universitas Kristen Satya Wacana dengan Menggunakan MediaWiki
}

\author{
Teofilus R. Y. Ngantung ${ }^{1}$ \\ Program Studi Sistem Informasi, Fakultas Teknologi Informasi Universitas Kristen Satya Wacana \\ email: 682012055@student.uksw.edu \\ Andeka Rocky Tanaama ${ }^{2}$ \\ Program Studi Sistem Informasi, Fakultas Teknologi Informasi Universitas Kristen Satya Wacana \\ Melkior N. N. Sitokdana ${ }^{3}$ \\ Program Studi Sistem Informasi, Fakultas Teknologi Informasi Universitas Kristen Satya Wacana
}

\begin{abstract}
ABSTRAK
Laboran merupakan unit pelaksana teknis yang bertanggung jawab menyediakan fasilitasfasilitas untuk kegiatan dan aktivitas yang dilakukan dalam laboratorium. Sebagian besar tenaga laboran di FTI UKSW masih berstatus mahasiswa. Dalam melaksanakan tugas laborannya terutama untuk mengatasi masalah-masalah yang terjadi di laboratorium biasanya hanya sesuai dengan pengetahuan yang dimilikinya. Penelitian ini bertujuan untuk merancang knowledge management system di laboran FTI UKSW sehingga mempermudah laboran memperoleh pengetahuan-pengetahuan dalam melaksanakan tugasnya. Metode yang digunakan dalam perancangan ini adalah metode prototype dan data diperoleh dari observasi dan wawancara. Kesimpulan penelitian ini adalah perancangan knowledge management system di laboran FTI UKSW membantu laboran memperolah pengetahuan dan meningkatkan kinerjanya. Saran penelitian ini adalah supaya melanjutkan penelitian ini pada pengembangan aplikasi berbasis mobile.
\end{abstract}

Kata Kunci: Knowledge Management System

\begin{abstract}
The laboratory is an implementing unit that is responsible for providing facilities for activities and activities carried out in the laboratory. Most of the SWCU FTI labors work as university students. In carrying out his laboratory duties, especially to overcome problems that occur in the laboratory only in accordance with the knowledge he has. This study aims to implement a knowledge management system in the laboratory. SWCU FTI. Access to science. The method used in this design is the prototype method and current measurement data and interviews. This research report is the design of KMS at the SWCU FTI laboratory assisting the laboratory to obtain knowledge and improve its performance. The suggestions for this research are to complete the research
\end{abstract}

Keywords: Knowledge Management System

\section{PENDAHULUAN}

Dalam sebuah organisasi knowledge yang dimiliki, secara keseluruhan dapat meningkatkan daya saing dan efisiensi kerja dari organisasi yang bersangkutan. Knowladge management pada dasarnya tentang mendapatkan knowledge yang benar kepada orang yang tepat pada waktu yang tepat. (Alan Frost, 2017). Definisi lainnya ia menyatakan bahwa: Knowledge management merupakan pengelolaan pengetahuan organisasi yang sistematis untuk menciptakan nilai dan memenuhi persyaratan taktis dan strategis. (Alan Frost, 2014). Kedua definisi ini merujuk bahwa knowledge management harus menciptakan/menyediakan alat, orang, pengetahuan, struktur yang tepat. Melalui knowledge management akan teridentifikasikan pengetahuan- 
pengetahuan yang dimiliki sebuah organisasi untuk meningkatkan kinerja dan menghasilkan berbagai inovasi. Inovasi dalam suatu organisasi dapat diperoleh melalui kreasi pengetahuan yang merupakan salah satu dimensi proses knowledge management.

Laboran merupakan unit pelaksana teknis yang bertanggung jawab menyediakan fasilitas laboratorium untuk berbagai kegiatan dan aktifitas yang akan dilakukan di laboratorium. Laboran juga dapat merupakan tenaga kependidikan yang bekerja dilaboratorium dan membantu proses pembelajaran mahasiswa. Keberadaan tenaga laboran sangatlah menentukan keberhasilan kemampuan akademik mahasiswa dalam kegiatan dilaboratorium. (Supriadi Rustad, 2012). Untuk itu, laboran sebaiknya memiliki soft skills dan hard skills yang memadai. Laboran hendaknya memiliki nilai inisiatif, tekun, cakap, kreatif, terampil, dan pengetahuan yang dikuasai. Laboran hendaknya membantu efisiensi, efektifitas dan produktifitas dari laboratorium yang dikelola oleh suatu instansi atau perguruan tinggi. Oleh karena itu pengetahuan yang dimiliki oleh seorang laboran sangat penting untuk menunjang sistem yang ada di laboratorium.

Laboratorium di Fakultas Teknologi Informasi (FTI) Universitas Kristen Satya Wacana (UKSW) dikelola oleh kepala laboratorium. Dalam menjalankan tugasnya, kepala laboratorium dibantu oleh tenaga-tenaga laboran. Tenaga laboran ini berfungsi untuk menyediakan fasilitas software dan hardware dan membantu pelaksanaan kegiatan-kegiatan yang dilaksanakan di laboratorium. Sebagian besar anggota laboran masih berstatus mahasiswa. Oleh karena itu dalam melaksanakan tugas sebagai laboran di FTI tentunya tidak bisa lepas dari masalah-masalah yang ada dalam laboratorium. Masalah yang sering terjadi di laboratorium biasanya pada hardware dan software. Tenaga laboran laboran di lingkungan FTI mengerjakan masalahmasalah yang terjadi dalam laboratorium sesuai dengan pengetahuan yang mereka miliki.

Untuk mempermudah laboran mengatasi masalah tentunya sangat diperlukan suatu sistem pengorganisasian pengetahuan yang baik terutama dari tenaga laboran. Pengorganisasian pengetahuan ini bertujuan untuk menciptakan tenaga laboran memiliki nilai inisiatif, kreatif, tekun, cakap, terampil dan menguasai pengetahuan dan mampu mentransfer pengetahuan. Sistem pengelolaan tersebut diharapkan mampu mengkoordinasikan penggunaan informasi, pengetahuan dan pengalaman dari tenaga laboran khususnya yang ada di FTI. Hal ini juga bermanfaat untuk setiap anggota laboran FTI yang baru agar mereka dapat mempelajari permasalahanpermasalahan yang sering terjadi, dan ketika mereka mangalami masalah dengan sistem yang ada dalam laboratorium mereka bisa langsung mengatasinya dengan pengetahuan yang mereka miliki.

Pengembangan knowledge management system menggunakan Seci model. Seci model merupakan model pembentukan organisasi pengetahuan yang ditemukan oleh Ikujiro Nonoka adalah Seci model. Seci adalah singkatan dari socialization, externalization, combination, internalization. Seci model ini merupakan hasil penelitian dalam "Knowledge Management" yang berkaitan dengan organisasi pembelajaran, administrasi bisnis dan sistem informasi. Nonaka mengemukakan bahwa pembentukan pengetahuan berkelanjutan sebagai sumber inovasi berkelanjutan dan inovasi berkelanjutan sebagai sumber 
keunggulan kompetitif yang berkelanjutan. (Shelley Evenson dan Hugh Dubberly, 2011). Hal ini mengandung makna bahwa ketika organisasi berinovasi, mereka tidak hanya memproses informasi dari luar untuk memecahkan masalah yang ada dan beradaptasi dengan lingkungan yang terus menurus berubah, melainkan mereka akan membentuk pengetahuan dan informasi baru dari dalam keluar, untuk mendefinisikan kembali masalah, solusi, proses untuk membentuk kembali lingkungannya.

Berdasarkan uraian di atas, peneliti melakukan penelitian tentang perancangan dan implementasi knowledge management pada laboran FTI UKSW dengan menggunakan MediaWiki sebagai wadah untuk berbagi pengetahuan. Adapun rumusan masalah yang diambil peneliti dalam penelitian ini adalah bagaimana perancangan dan implementasi knowledge management pada laboran FTI UKSW dengan menggunakan MediaWiki.

Penelitian yang dilakukan yang dilakukan oleh Melkior N.N. Sitokdana (2016) dengan judul: "Strategi Pengembangan E-Culture Berbasis Ap Iwol Menggunakan Seci Model". Penelitian ini menggunakan metode kualitatif deskriptif, dengan merumuskan strategi menggunakan Seci model dalam Knowledge Management. Dalam penelitian ini peneliti menyimpulkan bahwa pengembangan $e$-Culture berbasis Ap Iwol merupakan salah satu potensi yang harus dikembangkan dan didayagunakan untuk berbagai kepentingan. Potensi tersebut tercermin dari Alut (kebijaksanaan), Masop (ilmu pengetahuan) dan Ngolki (Expert) yang terdapat dalam Ap Iwol. Atas dasar itulah peneliti merekomendasikan pengembangan $e$-Culture berbasis Ap Iwol untuk dikembangkan karena para Ngolki yang berperan di Ap Iwol kini sudah berkurang, sementara generasi muda saat ini tidak banyak yang berniat untuk mendalami potensi lokal ini sehingga ancaman degradasi nilai-nilai lokal diambang kepunahan.

Selanjutnya, penelitian yang dilakukan oleh Irvanda Kurniadi (2011) dengan judul "Implementasi Knowledge Management System Sematic MediaWiki pada Devisi Operasional Perusahan Telekomunikasi". Dalam penelitiannya, knowledge management system dibangun dengan menggunakan MediaWiki sebagai framework. Hasil penelitiannya menunjukkan bahwa ada response time yang wajar. Untuk load testing dengan variasi ritual user menunjukkan kenaikan response time yang linier. Selanjutnya sistem yang diterapkan sudah sesuai terhadap perusahan dan cukup efektif dalam penggunaannya.

Kemudian penelitian yang dilakukan oleh Chris Cassandra, Johan Tambotoh \& Fredrik Samuel Papilaya (2015) dengan judul: "Pemanfaatan MediaWiki sebagai Knowledge Managemant Tools untuk Mendukung E-Learning". Dalam penelitian ini peneliti memilih MediaWiki sebagai salah satu dari banyak online collaboration tools. Pendekatan yang digunakan dalam penelitian ini adalah pengembangan sistem menggunakan pendekatan Design Science Reserch $(D S R)$. Untuk memastikan fungsi dari sistem yang dikembangkan berjalan baik, dilakukan uji coba di dua kelas matakuliah. Hasil penelitian ini menunjukkan bahwa mahasiswa berhasil berkolaborasi dengan baik dalam pembelajarannya. Penelitian ini membuktikan MediaWiki dapat dijadikan alternatif media pembelajaran serta mendukung upaya implementasi paradigma student-centered learning. 
Dari ketiga penelitian ini disimpulkan sebagai berikut. Pertama, Seci model dalam knowlwdge management dikembangkan dan digunakan untuk berbagai kepentingan kelompok atau instansi. Kedua, knowledge management system dibangun dengan menggunakan MediaWiki memberikan renponse time yang wajar sehingga dapat digunakan oleh instansi/perusahan. Ketiga, knowledge management system yang dibangun dengan MediaWiki mampu membangun hubungan/interaksi yang baik antara mahasiswa dan dosen sehingga dapat dijadikan sebagai alternatif media pembelajaran yang menekankan studentcented learning.

Adapun persamaan penelitian yang akan dilakukan oleh peneliti dengan kedua penelitian di atas adalah pertama, penelitian ini akan merancang suatu sistem dengan menggunakan MediaWiki. Dan kedua, penelitian ini mengimplementasikan knowledge Management System. Selanjutnya, perbedaan penelitian yang akan dilakukan oleh peneliti dengan kedua penelitian adalah sebagai berikut. Pada penelitian pertama dilakukan untuk meningkatkan efektivitas kinerja pada devisi operasional perusahan telekomunikasi dan pada penelitian kedua bertujuan membuat media pembelajaran alternatif dan memberikan upaya implementasi paradigma student-centered learning. Sedangkan pada penelitian yang akan dilakukan dapat bermanfaat untuk memudahkan para laboran mengakses pengetahuannya khususnya laboran FTI UKSW.

Teknologi informasi dewasa ini menjadi hal yang sangat penting karena sudah banyak organisasi yang menerapkan teknologi informasi untuk mendukung kegiatan organisasi. Teknologi Informasi (TI) memiliki banyak sekali pengertian.
Gunawan mengemukakan beberapa definisi teknologi informasi, antara lain: Haag dan Kenn (1966) mendefinisikan teknologi informasi sebagai seperangkat alat yang membantu untuk bekerja dengan informasi dan melakukan tugastugas yang berhubungan dengan pemrosesan informasi. Sejalan dengan definisi tersebut Mc Keown (2001) mendefinisikan Teknologi Informasi merujuk pada seluruh bentuk teknologi yang digunakan untuk menciptakan, menyimpan, mengubah, dan untuk menggunakan informasi tersebut dalam segala bentuknya. Selanjutnya, Kenneth C.Loudon (2004) mendefinisikan Teknologi Informasi adalah salah satu alat yang digunakan para manajer untuk mengatasi perubahan yang terjadi.

Menurut ITAA (Information Technology Association of America), Pengertian Teknologi Informasi adalah suatu studi, perancangan, implementasi, pengembangan, dukungan atau manajemen sistem informasi berbasis komputer, terkhususnya pada aplikasi perangkat keras dan perangkat lunak komputer. (Sepridahanum, 2017). Hal ini menunjukkan bahwa teknologi informasi memanfaatkan komputer elektronik dan perangkat lunak komputer untuk mengubah, menyimpan, memproses, melindungi, mentransmisikan dan memperoleh informasi secara aman. Definisidefinisi tersebut merujuk bahwa teknologi informasi menyatukan komputasi dan komunikasi berkecepatan tinggi untuk data, suara, dan video. Contoh dari Teknologi Informasi bukan hanya berupa komputer pribadi, tetapi juga telepon, TV, peralatan rumah tangga elektronik, dan peranti genggam modern (misalnya ponsel).

Teknologi Informasi diterapkan guna untuk pengelolaan informasi yang pada saat ini menjadi salah satu bagian penting karena : 1) karena meningkatnya 
kompleksitas dari tugas manajemen, 2) karena pengaruh ekonomi internasional (globalisasi), 3) karena perlunya waktu tanggap (respons time) yang lebih cepat, dan 4) karena tekanan akibat dari persaingan bisnis. Seprida Hanum (2017). Sejalan dengan pengertian di atas maka tujuan Teknologi Informasi adalah untuk memecahkan suatu masalah, membuka kreativitas, meningkatkan efektivitas dan efisiensi dalam melakukan pekerjaan. Jadi dapat dikatakan karena dibutuhkannya pemecahan masalah, membuka kreativitas dan efisiensi manusia dalam melakukan pekerjaan, menjadi penyebab atau acuan diciptakannya teknologi informasi. Dengan adanya teknologi informasi membuat pekerjaan manusia menjadi lebih mudah dan efisien.

$$
\text { Selanjutnya, Sutarman }
$$
mengemukakan enam fungsi teknologi informasi yaitu : 1) sebagai penangkap (Capture), 2) sebagai pengolah (Processing), 3) sebagai penghasil (Generating), 4) sebagai Penyimpan (storage), 5) sebagai Pencari Kembali (Retrifal), dan 6) sebagai Transmisi (Transmission). Knowledge merupakan kemampuan seseorang/individu dalam menghubungkan dan mengaitkan setiap informasi yang dimiliki olehnya dengan konsep-konsep lain yang relevan dengan area tertentu untuk digunakan dalam proses pengambilan keputusan. Selanjutnya, Schneider (2009) mengemukakan bahwa knowledge erat kaitannya dengan konteks yang menentukan relevansi sebuah informasi terhadap situasi atau kondisi tertentu. Knowledge punya keterkaitan dengan data dan informasi. Data adalah unit terkecil yang bersifat statis, yang merupakan representasi dari fakta, observasi, dan persepsi dalam keseharian, sedangkan informasi bersifat dinamis. Dari pernyataan tesebut dapat dikatakan bahwa knowledge merujuk pada informasi yang mengandung action dan decisions. Knowledge didefinisikan sebagai data dan informasi yang digabung dengan kemampuan, intuisi, pengalaman, gagasan, motivasi dari sumbersumber yang kompeten (Irvanda, 2011).

Knowledge terdiri atas tacit dan explicit. Tacit knowledge meliputi wawasan, intuisi, dan dugaan. Tacit knowledge sulit diekspresikan dan dirumuskan sehingga knowledge ini sulit untuk dibagi. Explicit knowledge merupakan suatu knowledge yang dapat direpresentasikanke dalam bentuk angka dan huruf sehingga knowledge ini dapat dibagi secara sistematis dalam bentuk data, suara, gambar, spesifikasi, program komputer dan sebagainya. Management berarti merencanakan, mengumpulkan dan mengorganisir, mengoordinasikan resource untuk suatu tujuan. Knowledge Management dapat diartikan sebagai proses yang mengoordinasikan penggunaan informasi, pengetahuan dan pengalaman (Irvanda, 2011). Berdasarkan pernyataan di atas, Knowledge Management didefinisikan sebagai proses bisnis untuk memperoleh, mengelola dan mengomunisasikan tacit knowledge maupun explicit knowledge sehingga memungkinkan orang lain untuk menggunakannya secara lebih efektif dan produktif.

Seci model berasal dari hasil penelitian tentang "knowledge management" yang berhubungan dengan pengorganisasian pembelajaran, administrasi bisnis dan sistem informasi. Salah satu teori yang paling terkenal dari pembentukan pengetahuan organisasi adalah Spiral Pengetahuan Nonaka (Nonaka's Spiral of Knowledge). Nonaka mengemukakan empat model konversi pengetahuan yang dibangun ketika tacit dan explicit knowledge berinteraksi, yaitu: 
proses sosialisasi, eksternalisasi, kombinasi dan internalisasi.

\section{METODE}

Metode perancangan sistem dalam penelitian ini menggunakan metode prototype. Dalam Model Prototype, prototype dari perangkat lunak yang dihasilkan kemudian dipresentasikan kepada pelanggan, dan pelanggan tersebut diberikan kesempatan untuk memberikan masukan sehingga perangkat lunak yang dihasilkan nantinya betul-betul sesuai dengan keinginan dan kebutuhan pelanggan. Rancangan model prototype yang dilakukan dalam penelitian ini adalah dengan merancang knowledge management model Seci dengan menggunakan MediaWiki. Ada ketiga tahap yang akan dilakukan pada model prototype yaitu: listen to customer, build/revise mack-up, dan customer tes drives mack-up.

Tahap Listen to customer merupakan tahap pengumpulan kebutuhan. Pengumpulan kebutuhan dilakukan melalui pertemuan antara pengguna dan pengembang. Pengguna dalam penelitian ini ialah kepala dan tenaga laboran yang ada di FTI UKSW. Sedangkan pengembang adalah penulis sendiri selaku subjek yang melakukan penelitian. Hal-hal yang dibahas pada pertemuan awal meliputi tujuan, kebutuhan yang diketahui dan hal-hal yang dibutuhkan berikutnya. Untuk mendapatkan data kebutuhan penelitian ini dilakukan dengan cara: observasi, wawancara dan kajian pustaka. Observasi dan wawancara dilakukan kepada supervisior laboran yang ada di FTI UKSW. Sedangkan kajian pustaka dilakukan peneliti dengan menggali informasi dari bukubuku, skripsi dan jurnal tentang teori yang berkaitan dengan judul yang digunakan.
Tahap build/revise mack-up terdiri atas tahap perancangan sistem dan implementasi sistem. Tahap perancangan sistem akan dibangun knowledge managemen system dengan Seci model. Untuk dapat menjelaskan rincian yang dapat dilakukan pada sistem yang akan dirancang, maka diperlukan gambaran alur sistem dalam hal ini dipilih Unified Modeling Language (UML) use case dan diagram activity.

Tahap implementasi dilakukan oleh pengguna terhadap prototype yang dibangun. Apabila prototype sudah sesuai dengan keinginan pengguna. Dengan kata lain, evaluasi ini dilakukan untuk menetapkan apakah penelitian ini dilanjutkan ke tahap berikutnya atau diulang kembali mulai langkah 1. Apabila prototype suda sesuai dengan keinginan pengguna maka akan dilanjutkan dengan pengkodean system. Pada tahap ini prototype yang sudah diterima oleh pengguna dibuat menjadi software. Software yang dibangun menggunakan MediaWiki. Software yang dibangun ini berfungsi untuk mempermudah tenaga laboran dalam mengakses informasi.

Tahap terakhir adalah tahap customer tes drives mack-up. Pada tahap ini akan dilakukan pengujian software. Pengujian software dilakukan melalui wawancara dengan semua tenaga laboraran sebagai pengguna. Selanjutnya akan dilakukan evaluasi software. Evalusi software dilakukan setelah pengujian software. Evaluasi software dilakukan menentukan apakah software yang dibuat dapat digunakan. Langkah terakhir pada tahap ini adalah implementasi. Setelah pengujian dilakukan dan hasilnya positif, maka software siap untuk digunakan oleh tenaga laboratorium. 


\section{HASIL DAN PEMBAHASAN}

Dalam menyusun model awal menggunakan Model Linear Programming (LP), tim melakukan observasi lapangan untuk mengumpulkan data-data yang diperlukan.

Metode perancangan sistem ini menggunakan Unified Modeling Language (UML) yang terdiri dari use case diagram dan activity diagram.

Use case diagram digunakan untuk menggambarkan interaksi antara pengguna sistem (actor) dengan use case yang disesuaikan dengan langkah-langkah yang telah ditentukan. Use case diagram tidak menjelaskan secara detail tentang penggunaan use case, namun hanya memberi gambaran singkat hubungan antara use case, actor dan system. Melalui use case diagram dapat diketahui fungsifungsi apa saja yang ada pada sistem. Berikut use case diagram knowledge management system di laboran.

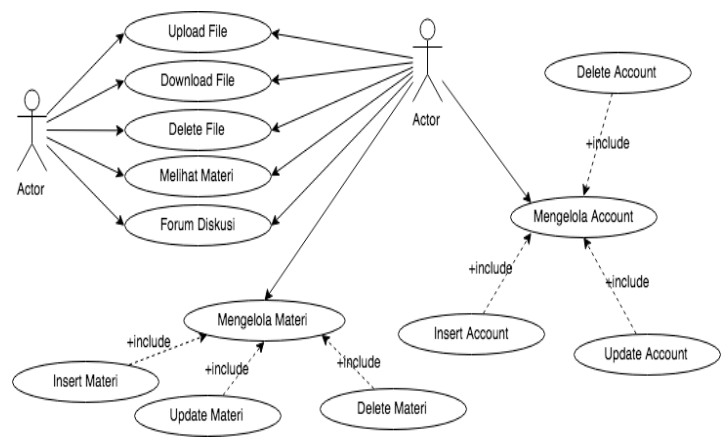

Gambar 1. Use case diagram knowledge management system di laboran

Pada gambar 1 menunjukkan use case diagram yang dilakukan oleh admin dan laboran. Aktor laboran merupakan pengguna yang memiliki akses upload file (artikel dan jurnal), download file (artike dan jurnal), forum discussion dan melihat materi. Aktor admin menjadi user yang memiliki hak akses penuh dalam knowledge management system ini, sehingga memerlukan login sebagai admin untuk bisa mendapat fasilitas- fasilitas sebagai seorang admin. Admin mempunyai tanggung jawab penuh terhadap sistem ini, seperti mengelola account (insert, update dan delete acount laboran).

Activity diagram adalah activity atau workflow dari sistem atau menu yang ada pada aplikasi. Activity diagram diperlukan untuk menggambarkan proses bisnis dan urutan aktivitas dalam sebuah proses.

Activity diagram digunakan untuk mendefinisikan urutan atau pengelompokan tampilan dari sistem atau user interface.

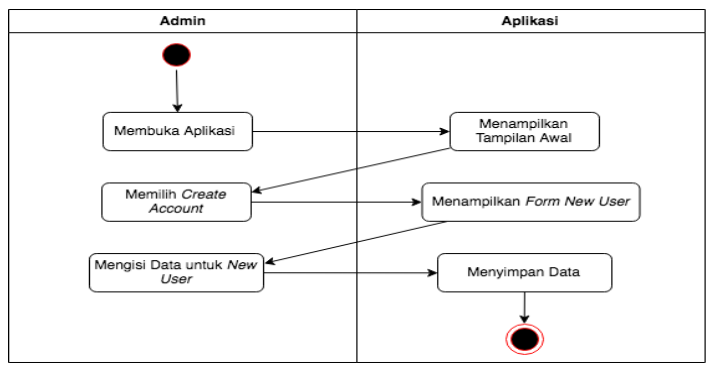

Gambar 2 Activity diagram Admin membuat user baru

Create user ini hanya bisa diakses oleh admin. Gambar 2 menjelaskan tentang cara admin membuat user baru. Yang pertama memilih create account pada Management user, maka aplikasi akan menampilkan form untuk new user. Setelah mengisi form, pilih create another account. Secara otomatis akan tersimpan dalam database.

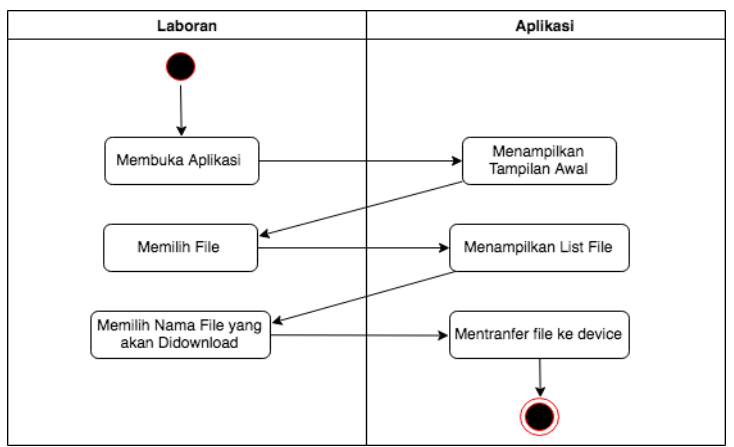

Gambar 3 Activity diagram download document 
Fasilitas untuk download ini bisa dilakukan oleh admin dan laboran. Pada gambar 3 dijelaskan mengenai cara untuk download. Setelah login, pilih file pada management file. Aplikasi akan menampilkan list file, kemudian pilih dokumen yang akan didownload. Secara otomatis dokumen akan ditranfer ke device.

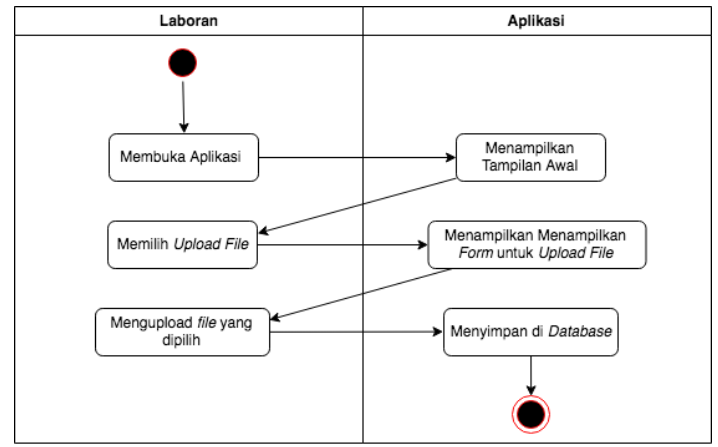

Gambar 4 Diagram activity upload document

Aktivitas ini bisa diakses oleh admin dan laboran. Pada gambar 4 menjelaskan tentang cara untuk upload document. Setelah login, pilih upload file pada management file. Kemudian aplikasi akan menampilkan form untuk upload file. Pilih document yang akan diupload, kemuadian pilih upload file. Secara otomatis document akan tersimpan di database.

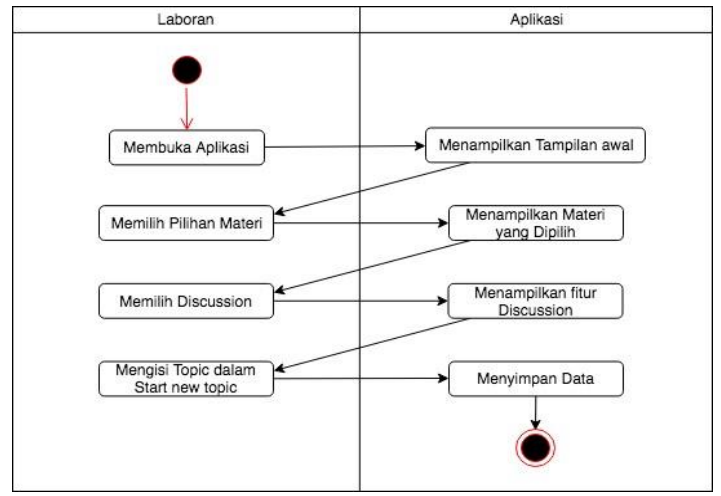

Gambar 5 Activity diagram laboran melakukan Discussion
Aktivitas ini dilakukan oleh laboran. Gambar 5 menjelaskan mengenai user (laboran) melakukan discussion. Untuk melakukan aktivitas ini laboran harus memilih materi dalam content. Kemudian aplikasi akan menampilkan materi yang dipilih. Selanjutnya pilih discussion, maka aplikasi akan menampilkan fitur untuk discussion. Laboran bisa mengisi topic yang akan dibicarakan. Kemudian data itu akan tersimpan dalam database.

\section{Implementasi}

Tujuan dari perancangan ini adalah untuk membangun knowledge management system di laboran FTI UKSW dengan menggunakan pendekatan seci model sehingga dapat berguna sesuai kebutuhannya. Perancangan sistem juga diharapkan berfungsi sebagai media yang dapat membantu pelaksanaan kerja labaron saat terjadi masalah. Dalam knowledge management sistem laboran terdapat tampilan login, disini user diharuskan melakukan login sebagai admin atau laboran.

\section{Sosialisasi (Socialization)}

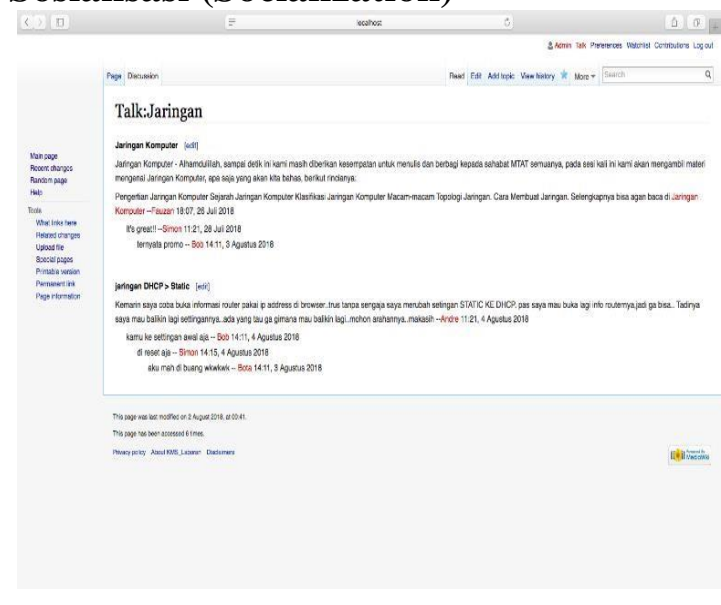

Gambar 6 Halaman Discussion

Proses sosialisasi ini adalah tahap di mana komunikasi terjadi di antara beberapa laboran, seperti yang dapat dilihat pada 
gambar 6. Dalam knowledge management system di laboran difasilitasi dengan discussion dimana user dapat berdiskusi tentang suatu topic sehingga memunculkan knowledge sharing yang dapat meningkatkan pengetahuan setiap individu. Oleh karena itu tahapan ini dapat dikatakan sebagai Sosialisasi (Socialization).

\section{Eksternalisasi (Externalization)}

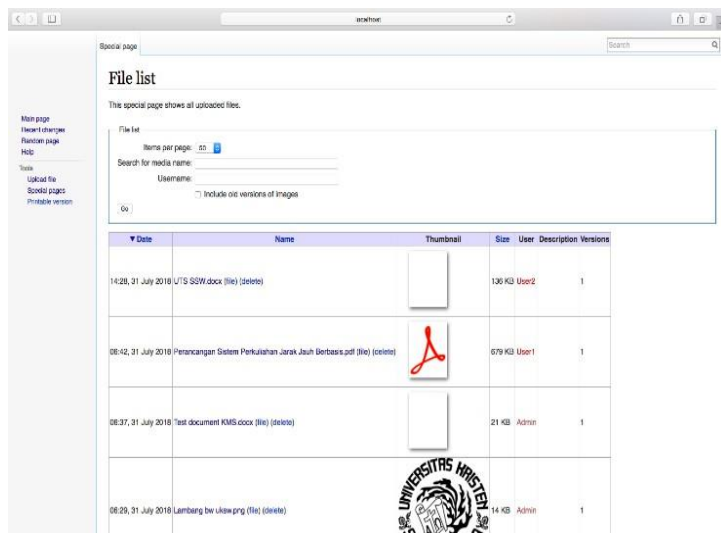

Gambar 7 Halaman file list yang berisikan file yang upload

Pada tahapan ini admin dan laboran dapat mengupload file berupa document, gambar dan audio. Semua file yang diupload akan tersimpan dalam database. Dapat dilihat pada gambar 4.7 terdapat file berupa gambar dan dokumen yang sudah diupload. Tahapan ini disebut juga eksternalisasi (Externalization) karena adanya perpindahan knowledge dari tacit ke explicit.

\section{Kombinasi (Combination) dan \\ Internalisasi (Internalization)}

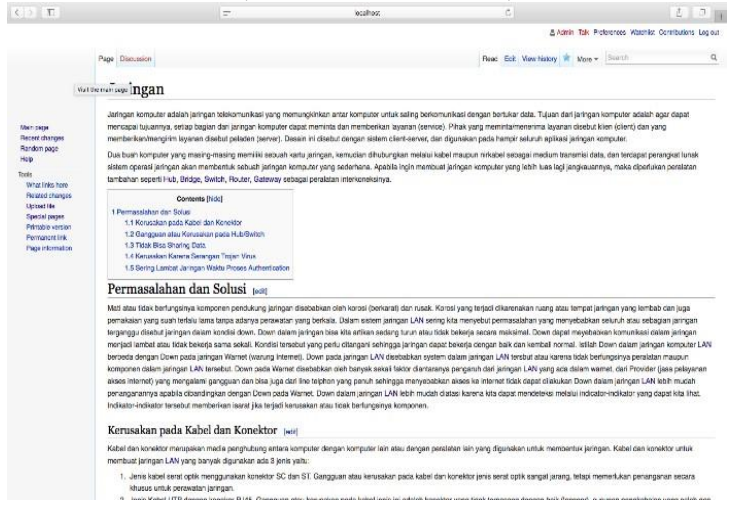

Gambar 8 Halaman materi jaringan

Gambar 8 merupakan halaman dari materi jaringan. Dalam materi juga dijelaskan tentang masalah yang sering terjadi serta penangannya.

Tahap ini juga dapat di katagorikan sebagai Kombinasi (Combination), maupun Internalisasi (Internalization) karena dengan melakukan pembelajaran dari materi, seorang laboran kemungkinan menciptakan pengetahuan baru.

\section{Testing Aplikasi}

Setelah tahap perancangan dan pembuatan aplikasi, maka pada tahap akhir dilakukan pengujian aplikasi untuk mengetahui aplikasinya dapat berjalan dengan baik. Peneliti menggunakan metode black-box untuk pengujiannya. Metode ini memfokuskan pada keperluan fungsional software. Pengujian black-box ini merupakan pengujian fungsional tanpa melihat alur aksekusi program, namun cukup dengan memperhatikan apakah setiap fungsi berjalan dengan baik sesuai kegunaannya. Berikut tabel pengujian sistem dapat dilihat pada tabel 1 . 
Tabel 1 Pengujian aplikasi knowledge management system di laboran

\begin{tabular}{|c|c|c|c|c|}
\hline$\overline{\text { No. }}$ & Pengujian & Kondisi & Respon System & Status \\
\hline 1. & Login & $\begin{array}{l}\text { - Menginput id dan password benar } \\
\text { - Menginput id dan password salah }\end{array}$ & $\begin{array}{l}\text { Masuk ke halaman } \\
\text { utama } \\
\text { Tetap di halaman } \\
\text { user login }\end{array}$ & $\begin{array}{l}\text { Berhasil } \\
\text { Berhasil }\end{array}$ \\
\hline 2. & $\begin{array}{l}\text { Menu } \\
\text { Create } \\
\text { Account }\end{array}$ & $\begin{array}{l}\text { - Admin klik menu create account } \\
\text { - Laboran klik menu create account }\end{array}$ & $\begin{array}{l}\text { - Menampilkan } \\
\text { form create } \\
\text { account } \\
\text { Tetap ke halaman } \\
\text { utama }\end{array}$ & Berhasil \\
\hline 3. & $\begin{array}{l}\text { Manage ment } \\
\text { File }\end{array}$ & $\begin{array}{l}\text { - Admin/labor an upload file } \\
\text { - Admin/laboran delete file } \\
\text { - Admin/laboran download file }\end{array}$ & $\begin{array}{l}\text { - Menampilkan data } \\
\text { - } \quad \text { Filead langsung } \\
\text { terhapus } \\
\text { - File langsung ter- } \\
\text { download }\end{array}$ & $\begin{array}{l}\text { Berhasil } \\
\text { Berhasil } \\
\text { Berhasil }\end{array}$ \\
\hline 4. & $\begin{array}{l}\text { Content dari } \\
\text { Admin }\end{array}$ & $\begin{array}{l}\text { - Admin update materi } \\
\text { - Admin insert materi } \\
\text { - Admin delete materi }\end{array}$ & $\begin{array}{ll}\text { - } & \text { Materi terupdate } \\
\text { - } & \text { Materi tersimpan } \\
& \text { Materi langsung } \\
& \text { terhapus }\end{array}$ & $\begin{array}{l}\text { Berhasil } \\
\text { Berhasil } \\
\text { Berhasil }\end{array}$ \\
\hline 5 & $\begin{array}{l}\text { Content dari } \\
\text { laboran }\end{array}$ & $\begin{array}{l}\text { - Laboran melihat materi } \\
\text { - Laboran melakukan diskusi dalam } \\
\text { discussion }\end{array}$ & $\begin{array}{l}\text { - } \text { Manampilkan } \\
\text { materi } \\
\text { - Menampilkan Form } \\
\text { discussion }\end{array}$ & $\begin{array}{l}\text { Berhasil } \\
\text { Berhasil }\end{array}$ \\
\hline
\end{tabular}

Untuk mengetahui manfaat yang diperoleh dari aplikasi ini, digunakan metode kualitatif dengan melakukan wawancara kepada supervisior laboran. Dari wawancara didapatkan bahwa knowledge managemen system ini sudah sesuai dengan kebutuhan saat ini.

\section{PENUTUP}

\section{Kesimpulan}

Berdasarkan hasil pembahasan perancangan knowledge management system di laboran FTI UKSW yang menggunakan metode pengembangan sistem prototype dapat disimpulkan bahwa knowledge management system yang dibuat sangat membantu laboran FTI untuk memperoleh pengetahuanpengetahuan yang dibutuhkan dalam meningkatkan kinerjanya. Adanya fitur materi, download file, uplaod file dan forum diskusi memberikan dampak pada peningkata pengetahuan menjadi pengetahuan yang baru.

\section{Saran}

Dari hasil penelitian ini maka disarankan supaya pengembangan aplikasi ditingkatkan menjadi aplikasi berbasis mobile. Dengan aplikasi berbasis mobile dapat memudahkan laboran bekerja mengingat sebagian besar laboran FTI UKSW masih berstatus sebagi mahasiswa

\section{DAFTAR PUSTAKA}

Irvanda Kurniadi (2011). Implementasi Knowledge Management system berbasis Sematic MediaWiki pada Divisi Operasional perusahaan Telekomunikasi. 
Nonaka, I., \& Toyama, R., \& Konno, N. (2001). SECI, ba and leadership: A unified model of dynamic knowledge creation. In I. Nonaka \& D. J. Teece (Eds.), Managing industrial knowledge: Creation, transfer and utilization (pp. 13-39). London: Sage.

Chris Cassandra, Johan Tambotoh, dan Frederik Samuel Papilaya (2015). Pemanfaatan MediaWiki sebagai Knowledge Management tools untuk Mendukung Implementasi $E$ Learning.

Evenson, Shelley \& Dubberly, Hugh. 2011. Design as Learning-or "Knowledge Creation" -The SECI Model.http://www.dubberly.com/artic les/design-aslearning.html (accessed February 19th, 2018)

Rustad, Supriadi. 2012. Pedoman Umum

Pemilihan Laboran Berprestasi. Jakarta: KEMENDIKBUD DIRJEN DIKTI.

Kurt, Schneider, (2009). Experience and

Knowledge Management in Software Engineering. Germany: SpringerVerlag

Berlin Heidelberg

Bacerra-Fernandez, Irma, Avelino Gonzalez, and Rajiv Shaberwal. (2003). Knowledge

Management: Challanges, Solution and Technologies. New Jersey: Pearson Education.

Seprida Hanum (2017). Belajar dan Berkreasi:

Pembelajaran Digital. http://sepridahanum.web.id/pengerti anfungsi-dan-tujuan-teknologiinformasi/

((accessed February 18th, 2018)

Sutarman, 2009. Pengantar Teknologi Informasi.

Penerbit Bumi Aksara : Jakarta.

Angon. 15 April 2016. Macam-macam Model Pengembangan Perangkat Lunak dan contoh penerapan. https://www.angon.co.id/news/uncat egorize d/model-modelpengembangan-perangkatlunakbeserta-contoh-penerapannya. (accessed February 19th, 2018)

Murti. 25 Agustus 2014. Model-model Pengembangan Perangkat Lunak beserta contoh Penerapannya. https://murtri.wordpress.com/2014/0 8/25/mo del-model-pengembanganperangkat-lunakbeserta-contohpenerapannyal. (accessed

February 19th, 2018)

Sitokdana, Melkior N.N. 2016. Strategi Pengembangan E-Culture Berbasis Ap-Iwol Menggunakan SECI Model. Prosiding: Annual Research Seminar 2016 (Vol 2 No.1: 6 Desember 2016). Jakarta: UNSRI.

Frost, A. 2014. A Synthesis of Knowledge Management Failure Factor. http://www.knowledgemanagementtools.net/knowledgemanagementdefinition.html. (accessed February 20th, 2018)

Frost, A. 2017. Knowladge Management Tools. $\quad$ http://www.knowledgemanagementtools.net/. (accessed February 20th, 2018)

Gunawan, Tegar chandra. 2011. Pengertian Teknologi Informasi 
T. Ngantung 1 , A. Tanaama ${ }^{2}$,

Menurut Para Ahli.

http://30211259.blogspot.co.id/2011/

09/pen gertian-teknologi-informasimenurut.html. (accessed February

20th, 2018) 